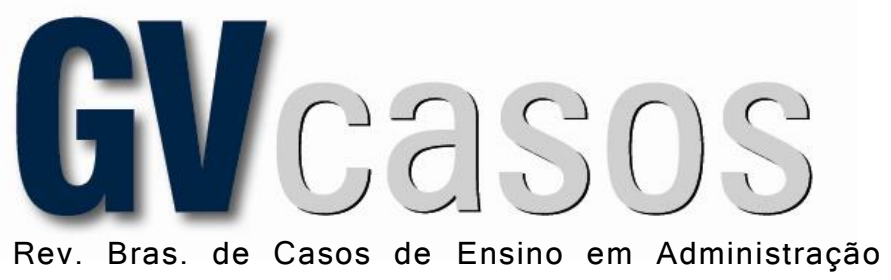

DOI: http://dx.doi.org/10.12660/gvcasosv11n1c3

\title{
CONSTRUTORA MEIRELES \& SILVA: IMPACTO DO VIÉS INCONSCIENTE NA CARREIRA DAS MULHERES
}

Meireles \& Silva Constructors: impact of unconscious bias in women career

\author{
Cristina Kerr de BARros Pereira - criskerr@ ckzdiversidade.com.br \\ Escola de Administração de Empresas de São Paulo da Fundação Getulio Vargas - São Paulo, SP, \\ Brasil
}

GuSTAVo ANDREy DE ALMEIDA LOPES FERNANDES - gustavo.fernandes@ fgv.br

Escola de Administração de Empresas de São Paulo da Fundação Getulio Vargas - São Paulo, SP, Brasil

\begin{abstract}
Resumo
Ricardo e Alfonso fundaram a Construtora Meireles \& Silva há mais de 20 anos, quando se formaram na faculdade. Porém, uma situação sempre incomodava Ricardo: o baixo número de mulheres em posições de liderança na sua empresa. Após participar de uma palestra sobre Diversidade e Inclusão num evento de inovação, ficou clara para Ricardo a origem dessa situação. Juntamente com seu sócio, eles começaram uma mudança na empresa. Mas será que toda a liderança estava alinhada? Quais seriam os maiores desafios e as principais barreiras para a diversidade de gênero acontecer na construtora e como superá-los?

Palavras-chave: Crenças, estereótipo, gênero, viés inconsciente, preconceito.
\end{abstract}

\begin{abstract}
Ricardo and Alfonso founded Construtora Meireles \& Silva more than 20 years ago when they graduated from college. However, one situation always bothered Ricardo: the low number of women in leadership positions in his company. After participating in a lecture on Diversity and Inclusion in an innovation event, it was clear to Ricardo the origin of this situation. Together with Alfonso, they started a change in the company. But was all the leadership team aligned? What would be the biggest challenges and the main barriers to gender diversity happening in the company and how to overcome them?
\end{abstract}

Keywords: Beliefs, gender, prejudices, stereotypes, unconscious bias.

\section{Construtora Meireles \& Silva}

A história da Construtora Meireles \& Silva começa na década de 1990, quando Ricardo e Alfonso, ao terminarem a faculdade, decidiram abrir sua própria empresa.

Alfonso Meireles seguira os passos de seu pai, Marcos Meireles, também engenheiro. Dentro de casa, Alfonso cresceu vendo sua mãe se dedicando aos afazeres domésticos enquanto seu pai era o provedor da casa. Dessa maneira, Alfonso passou a acreditar que deveria seguir o modelo do seu pai.

$\mathrm{Na}$ faculdade, Alfonso conheceu Ricardo Silva. Ele era filho de um professor de Matemática e de uma engenheira, de quem recebeu o estímulo para seguir carreira. Ricardo crescera admirando sua mãe, pois via sua dedicação no trabalho. Porém se lembrava da decepção dela quando descobriu que ganhava quase o mesmo salário que um engenheiro recém-formado contratado na empresa, mesmo ela tendo anos de experiência. Para Ricardo, saber que sua mãe, tão experiente e competente, 
ganhava o mesmo que um recém-formado foi chocante. Mas esse sentimento de indignação ficou adormecido.

Em 20 anos, a construtora virara referência no País. Porém havia uma situação que sempre incomodava Ricardo. Um padrão que vivenciara na faculdade e se repetia em todos os setores: só havia homens na liderança, com apenas duas gerentes e uma diretora. Na escola de Engenharia, havia, no máximo, seis mulheres numa turma com 100 alunos. Ricardo pensava que algo estava errado, mas não compreendia o motivo pelo qual aquilo acontecia. Mas Alfonso parecia completamente desligado quanto a essa situação.

Na semana seguinte, Ricardo foi a um evento sobre inovação e, no último dia, participou de uma palestra sobre "Diversidade \& inclusão nas empresas". Diversos temas foram apresentados: diversidade na liderança, equidade de gênero, viés de gênero, estereótipos, crenças e vieses inconscientes. Ricardo, então, começou a descobrir o que estava errado com sua empresa. Quando a palestra terminou, Ricardo foi falar com a especialista, Luanny.

Ricardo: Tudo isso tenho visto dentro da minha própria empresa. Apesar de bons resultados, não temos inovado, e acho que poderíamos avançar mais se tivéssemos uma liderança mais diversa.

Luanny: Com certeza. Contudo, o primeiro passo é conscientizar a liderança. Sem o apoio e a compreensão deles, as chances de implementar um programa de diversidade são pequenas. Não podemos mudar se não soubermos onde está o problema. No caso da diversidade, o problema é mais sutil, pois muitas vezes ocorre de maneira inconsciente. É o que chamamos de viés inconsciente. Você sabia que a maioria das nossas decisões é tomada de maneira inconsciente?

Ricardo: Como assim, inconsciente?

Luanny: Por exemplo, na seção de vinhos do mercado toca uma música italiana. Só por isso, aumentam as chances de você comprar um vinho italiano. Os mercados utilizam essa estratégia para vender o vinho italiano, mas você não está consciente disso.

Ricardo: Ainda não consigo ver o impacto do inconsciente na questão do pequeno número de mulheres em cargos de liderança na empresa.

Luanny: O poder do cérebro inconsciente, aliado com os estereótipos, crenças e pressuposições que adquirimos durante nossa vida, dita a maneira de vermos o mundo. Vou fazer uma pergunta e gostaria que você me respondesse com a primeira imagem que pensar. Descreva para mim a figura de uma pessoa com o cargo de presidente de uma grande empresa.

Ricardo: Ele é um homem confiante, que inspira confiança nos outros. Ele tem seu escritório em Nova Iorque com uma bela vista do Central Park. Ele usa um terno refinado...

Luanny: Pode parar. Você descreveu um homem, certo? Você jamais pensaria em uma mulher.

Ricardo lembrou-se de sua mãe, do quanto era competente, mas nunca alcançou cargos de liderança. Nesse momento, tudo ficou claro.

Ricardo: A imagem de uma mulher como presidente de sucesso sequer passou pela minha mente. Por isso que há um número tão pequeno de mulheres estudando Engenharia e na minha empresa. Provavelmente é por isso também que minha mãe nunca subiu de cargo na empresa.

Luanny: Você acaba de dar o primeiro passo em prol da diversidade de gênero. Existem poucas mulheres na área de Ciências, Tecnologia, Engenharia e Matemática, porque nossas meninas escutam desde pequenas que não pertencem a essas áreas. Além disto, a maioria das referências nessa área também é masculina. Isso acaba criando na mente das meninas, de modo inconsciente, a ideia de que elas não pertencem a essas áreas, criando um estereótipo.

Ricardo: Haverá uma reunião com a diretoria da minha empresa, que é composta por mim, meu sócio, oito diretores, sendo apenas uma mulher, para decidirmos as estratégias de gestão deste ano. Gostaria de adicionar a pauta da diversidade e inclusão nessa reunião.

Luanny: Será uma honra participar dessa reunião. 

do tema.

Na segunda-feira, Ricardo e Alfonso estavam conversando, e Ricardo aproveitou para falar

Alfonso: Diversidade e inclusão? O que é isso?

Ricardo: É um dos assuntos mais importantes para as empresas atualmente. As grandes multinacionais estão tratando desse tema por trazer mais resultado e inovação para as corporações.

Alfonso: Nunca ouvi falar disso.

Ricardo: Por exemplo, todos os colaboradores do Google participam de um treinamento de conscientização sobre viés inconsciente e do programa de Valorização da Diversidade \& Inclusão. A Natura desenvolveu um plano para atingir a equidade de gênero e atingir $50 \%$ de mulheres em cargos de liderança, ter $100 \%$ de equidade salarial entre homens e mulheres, e licença-paternidade de 40 dias remunerada. Você já pensou por que será que havia um número tão pequeno de meninas estudando Engenharia?

Alfonso: Porque Engenharia é coisa para homens.

Ricardo: Quem foi que disse que as mulheres não levam jeito para Engenharia? modelo.

Alfonso: Acho que os homens são mais racionais, corajosos e fortes. Esse sempre foi meu

Ricardo: Mas isso não torna esse fato verdadeiro. Gostaria que você entendesse o que está por trás desse pensamento. Seu pai e avô trabalharam duro a vida toda, provendo para a família. E você também é o provedor da casa.

Alfonso: Exatamente. Meu avô e meu pai fizeram isso. Continuo no mesmo caminho, e até o momento não tenho do que reclamar.

Ricardo: Sua filha está com 15 anos, certo?

Alfonso: Isso mesmo.

Ricardo conhecia Beatriz, a filha de seu melhor amigo. Ele sabia que Beatriz tinha uma aptidão enorme para Exatas. E foi assim que conseguiu abrir os olhos de Alfonso.

Ricardo: Beatriz vai muito bem em Matemática, não é?

Alfonso: Sim, ela é a melhor da turma em Matemática, Física e Química.

Ricardo: Quando Beatriz estiver pronta para ingressar na faculdade e disser que quer ser engenheira, você por acaso dirá a ela que isso não é para mulheres? Tenho certeza de que não. Mas imagine quantas vezes nós escolhemos um engenheiro no lugar de uma engenheira baseados nas crenças e estereótipos que formamos ao longo da vida. Isso é o que os especialistas chamam de viés inconsciente. Eu conheci uma especialista no tema no evento da semana passada e a convidei para participar da nossa próxima reunião. Assim, ela pode explicar a questão da diversidade e inclusão e esclarecer nossas dúvidas.

Alfonso: Muito bem, Ricardo.

No dia da reunião, o primeiro tópico foi a promoção de um funcionário para ser gerente da nova filial. Alfonso pediu indicações. Gregório, líder da área de Gestão de Projetos, recomendou um candidato de sua equipe, Henrique, competente no que fazia, apresentava bons resultados, e acima de tudo, tinham estudado na mesma instituição.

Fernando, outro líder, indicou Mauro e Barbara. Contudo, ao se referir à candidata, disse: "Ela é competente, mas muito mandona e agressiva. Sempre tem que dar a última palavra. Penso que Mauro seria melhor nessa posição, pois é mais fácil de trabalhar".

Cássio sugeriu Rosangela para o cargo. Ela era uma excelente funcionária, uma mulher negra, que se destacava pelo seu conhecimento, proatividade e excelentes resultados. Contudo, tinha se formado numa universidade que, segundo os outros líderes, não era de primeira linha, e foi descartada.

Rogério indicou um jovem talento chamado Enzo. "Apesar da idade, 27 anos, ele é muito inteligente e proativo. Não tem muita experiência, mas tem um grande futuro pela frente. É um líder 
nato!". Rogério também tinha cogitado Fernanda, uma mulher de 30 anos, mas o consenso foi que ela ainda não estava preparada para assumir uma posição, apesar de ter três anos a mais de experiência que Enzo.

Ernesto, um dos líderes mais antigos, começou elogiando Daniela, mas lembrou que ela havia retornado há pouco de licença-maternidade, e disse: "Daniela tem todas as competências para esse cargo, mas acabou de retornar de licença-maternidade e estará muito ocupada daqui para a frente. Melhor escolhermos outro candidato".

Ricardo: Agora, gostaria de pedir que a Luanny, especialista em diversidade e inclusão, nos falasse sobre suas percepções até o momento.

Luanny: A diversidade de gênero implica diversidade de ideias, pensamentos e, portanto, melhores decisões dentro de uma corporação. Pesquisas mostram melhor desempenho financeiro nas empresas com uma liderança diversa. Porém, aqui na Construtora, quase não há mulheres em cargo de liderança, exceto a Vanessa. É comum mulheres como diretoras de RH, pois o nosso inconsciente associa mulheres como cuidadoras e relacionais. O fato de Vanessa ser diretora, apesar de bom, reforça nosso viés inconsciente. Gostaria, portanto, de retomar algumas falas que vocês trouxeram durante a reunião, referentes à promoção de uma pessoa. Alguns de vocês cogitaram boas candidatas. Contudo, cada uma delas foi descartada por motivos que aparentemente soam legítimos, mas que, na verdade, estão repletos de estereótipos e preconceitos sobre as mulheres. A primeira candidata descartada foi Bárbara, pois era muito "mandona e agressiva". Esse é um tipo de viés inconsciente comum, o viés de comportamento, em que esperamos um padrão de comportamento para cada pessoa. Quando a pessoa sai do padrão, recebe um julgamento negativo. Esperamos que as mulheres sejam submissas e mansas. Quando elas agem com assertividade e liderança, rotulamos como agressivas e mandonas. Esse viés penaliza as mulheres por serem assertivas e mostrarem características de liderança.

Luanny: A candidata Fernanda foi descartada, apesar de ter três anos de experiência a mais que o outro candidato, escolhido com base no seu potencial futuro. Isso é o viés de desempenho. Geralmente, homens são contratados ou promovidos com base em seu potencial para alcançar grandes coisas, e as mulheres, com base no que já conquistaram.

Luanny: Agora chegamos num dos vieses mais comuns e mais destrutivos para as carreiras das mulheres: o viés de maternidade. Líderes automaticamente pensam que mães não poderão mais se dedicar ao trabalho, ou não querem aceitar uma tarefa mais desafiadora no trabalho, simplesmente por terem um bebê. Na verdade, fazem suposições sem perguntar para as mulheres se elas gostariam ou não de assumir tal tarefa. A candidata Rosangela, a única negra citada, foi descartada por não ser formada numa universidade famosa. Automaticamente assumimos que a faculdade determina o potencial e a competência de uma pessoa. É muito importante olharmos a interseccionalidade. Os vieses inconscientes têm um impacto mais negativo ainda quando estamos lidando com dois preconceitos inconscientes: gênero e raça.

Luanny: Por fim, preciso comentar o caso do Henrique. Apesar de seus talentos, o líder falou com empolgação sobre o fato de ambos terem estudado na mesma instituição. Isso é o que chamamos de viés de afinidade. Nós somos atraídos por tudo o que é semelhante a nós mesmos, e, geralmente com base nas afinidades de gênero, hobby, faculdade etc., realizamos nossas escolhas. Isso ocorre, muitas vezes, de maneira inconsciente, baseado em nossas crenças culturais, estereótipos e preconceitos construídos ao longo de nossas vidas sobre determinados grupos. Entretanto, vocês puderam perceber o impacto negativo que esses vieses inconscientes têm na carreira das mulheres.

Alfonso e Ricardo explicaram como a questão da diversidade e inclusão seria prioridade para a Construtora dali para a frente. Em alguns meses, as mudanças na Construtora já podiam ser notadas. $\mathrm{O}$ número de mulheres em cargos de liderança aumentou. Bárbara foi promovida para gerente da nova filial, e Rosangela foi a primeira mulher negra da empresa a ser promovida para um cargo de 
liderança. $\mathrm{O}$ ambiente mais diverso começava a produzir inovação e retorno financeiro. Os diretores estabeleceram um comitê de Diversidade \& Inclusão para dar sequência ao plano de ação.

Você foi convidado(a) para integrar esse comitê, e a primeira reunião do grupo será na próxima semana. Nessa reunião, o comitê deve discutir:

- como reduzir os vieses inconscientes dos líderes e gestores da Construtora para aumentar o número de mulheres?

- quais podem ser os maiores desafios e as principais barreiras para a diversidade de gênero acontecer na Construtora e como superá-los? 